\title{
Chapter 6 \\ Diagnosing the Instructional Quality of Biology Lessons Based on Staged Videos: Developing DiKoBi, A Video-Based Simulation
}

\author{
Maria Kramer, Julia Stürmer, Christian Förtsch, Tina Seidel, Stefan Ufer, \\ Martin R. Fischer, and Birgit J. Neuhaus
}

This chapter's simulation at a glance

Domain

Teacher education

Topic

Diagnosing subject-specific challenging situations in biology instruction

Learner's task Identifying and describing biology-specific challenges in instruction, reasoning about them by linking their description to scientific theories, and proposing alternative teaching strategies

Target group Pre-service biology teachers in various stages of their studies and early career practitioners

Diagnostic mode Individual diagnosing

Sources of Interaction; observation of videotaped classroom situations information showing the behavior of a teacher and students

Special features Using the video-based simulation as an assessment and learning tool; use of the simulation links to the model of professional vision

M. Kramer $(\bowtie)$ J J Stürmer · C. Förtsch · B. J. Neuhaus

Biology Education, Faculty for Biology, LMU Munich, Munich, Germany

e-mail: maria.kramer@biologie.uni-muenchen.de; didaktik.biologie@1rz.uni-muenchen.de

\section{T. Seidel}

Friedl Schöller Endowed Chair for Educational Psychology, School of Education, Technical

University of Munich (TUM), Munich, Germany

S. Ufer

Chair of Mathematics Education, LMU Munich, Munich, Germany

M. R. Fischer

Institute for Medical Education, University Hospital, LMU Munich, Munich, Germany 


\subsection{Diagnosing in the Teaching Context}

Teachers need to create domain-specific learning activities in the classroom, as these activities strongly influence students' learning (Seidel \& Shavelson, 2007). Thus, professional knowledge about implementing these activities is a necessary prerequisite for teachers' performance in the classroom, and thus also for instructional quality (Förtsch et al., 2016, 2018b; Seidel \& Shavelson, 2007). University education should not only offer opportunities for pre-service teachers to gain professional knowledge in setting up these activities, but should also support pre-service teachers in applying their knowledge and developing their competences in assessing learning situations during actual teaching (Grossman \& McDonald, 2008). Assessing learning situations also means providing on-the-fly diagnoses (Shavelson et al., 2008). As mentioned in the introduction by Fischer et al. (2022), diagnosing describes the "process of goal-oriented collection and integration of case-specific information to reduce uncertainty in order to make [...] educational decisions" (Heitzmann et al., 2019). These educational decisions aim at achieving effective teaching that exhibits the characteristics of instructional quality within a given subject. For successful diagnosis of teaching and learning, an evidence-based approach seems to be a promising way to develop diagnostic competences (Helmke \& Lenske, 2013). Following Blömeke et al. (2015), diagnostic competences can be modeled as a continuum that encompassing dispositions, such as professional knowledge; situation-specific skills, such as noticing and reasoning; and an observable performance or an output, such as the quality of diagnostic results. The diagnostic results can be assessed in terms of both the accuracy and efficiency of the diagnosis (Südkamp \& Praetorius, 2017). Teachers' noticing of challenging classroom situations and their reasoning about them can vary depending on their professional knowledge (Seidel \& Stürmer, 2014; van Es \& Sherin, 2002). However, the execution of situation-specific skills during the diagnostic process eventually determines teachers' performance in the classroom (Blömeke et al., 2015). In turn, teaching performance also influences teachers' professional knowledge and situation-specific skills while planning, teaching, and reflecting upon instruction (Santagata \& Yeh, 2016; Hume et al., 2019). Thus, we assume bidirectionality for the development of diagnostic competences as well. In addition, researchers have emphasized that practical experience can positively affect teachers' professional development and thus also their development of diagnostic competences (Stahnke et al., 2016).

Therefore, teacher education should find ways to foster pre-service teachers' acquisition of professional knowledge and situation-specific skills as part of teachers' diagnostic competences. Video-based simulations such as DiKoBi (German acronym for "diagnostic competences of biology teachers in biology classrooms") are one way to foster diagnostic competences to assess learning situations. 


\subsection{Theoretical Background}

The following sections specify professional knowledge, situation-specific skills, and teachers' performance as indicators of teachers' diagnostic competences. Furthermore, ways of scaffolding these competences are outlined.

\subsubsection{Teachers' Professional Knowledge}

Based on the work of Shulman (1987), teachers' professional knowledge can be divided into three facets: content knowledge (CK), pedagogical content knowledge (PCK), and pedagogical knowledge (PK) (cf. Baumert \& Kunter, 2013; Blömeke et al., 2010; Förtsch et al., 2018a). According to these conceptualizations, teachers need to use all three knowledge facets when teaching in the classroom. More teaching experience often comes along with more organized and integrated knowledge structures about teaching (de Jong \& Ferguson-Hessler, 1996). De Jong and Ferguson-Hessler recognized that in-service teachers' domain-specific knowledge schemas can be described as organized and structured, whereas the pre-service teachers' knowledge base is characterized by superficial elements and missing links to fundamental principles relevant to the domain. Furthermore, research shows a positive relation between teachers' professional knowledge and expertise, on the one hand, and instructional quality on the other (Hill et al., 2007; Blömeke et al., 2010). Borko (2004) emphasized that in-service teachers can recall their knowledge and teaching strategies in varying situations in the classroom. Thus, to develop professional knowledge that is applicable and transferable in various teaching situations, pre-service teachers need opportunities to put their knowledge into practice (Darling-Hammond, 2010). Observing and evaluating teaching situations with regard to instructional quality can be seen as one step toward this practice. Observing teaching situations can call up teachers' knowledge and help them enhance their situation-specific cognitive structures by remembering and adapting solutions. Over time, this process leads to growing expertise (Kolodner, 1992; Prawat, 1989).

However, research is still needed to examine how professional knowledge influences diagnostic competences and how the acquisition of these competences can be fostered. Furthermore, previous research has pointed out that different routes for the acquisition of professional knowledge exist. Kleickmann et al. (2017) note that in the sequence of addressing each knowledge facet (CK, PCK, and PK) within the process of knowledge acquisition is important. However, further research is needed to investigate the effects of different ways of fostering professional knowledge on diagnostic competences. 


\subsubsection{Situation-Specific Skills for Diagnosing}

Situation-specific skills are an important mediator between teachers' dispositions and their performance. When observing classroom situations, teachers use situationspecific skills to diagnose the situation and derive an appropriate teaching action resulting from their diagnosis (Borko et al., 2008). Though different conceptualizations of situation-specific skills exist, they all describe aspects of reasoning processes. Within teacher education, different conceptualizations for describing teachers' professional competences have already been compared and used to complement understanding of teachers' competences (Santagata \& Yeh, 2016; Blömeke $\&$ Kaiser, 2017). Whereas previous research solely focused on teachers' individual characteristics, the complementary frameworks also considered situational and social dependencies of teachers' development of professional competences (Blömeke et al., 2015). However, an interdisciplinary comparison has not yet been conducted, even though researchers have emphasized that comparing and combining conceptualizations of reasoning and argumentation might bring benefits for science education and thus for science teacher education as well (Bricker \& Bell, 2008). In this vein, O'Donnell and Levin (2001) described an increasing number of perspectives and principles from psychology that have been adopted in education. We focus on comparing two representative situation-specific skills that are relevant in the context of diagnosing - one commonly used in teacher education and one commonly used in psychology (see Table 6.1). Furthermore, these two representative skills are considered as relevant representations of models used across the different projects included in this volume. Thus, we expect clarification in terms of greater understanding across the interdisciplinary projects as well.

Researchers on teachers' expertise describe professional vision as an important situation-specific skill to improve instructional quality (Stürmer \& Seidel, 2015; Kersting et al., 2012; Goodwin, 1994). Professional vision includes the ability to notice classroom events that are relevant for students' learning as well as the ability to reason about these events (Seidel \& Stürmer, 2014; van Es \& Sherin, 2002). When teachers reason about noteworthy classroom events, three reasoning skills are crucial: description, explanation, and prediction. Description is conceptualized as teachers stating "relevant aspects of a noticed teaching situation and learning

Table 6.1 Systematizing situation-specific skills for diagnosing classroom situations

\begin{tabular}{l|l}
\hline \multicolumn{2}{l}{ Situation-specific skills for diagnosing (Blömeke et al., 2015) } \\
\hline Professional vision (Seidel \& Stürmer, 2014) & Diagnostic activities (Heitzmann et al., 2019) \\
\hline - Noticing & $\bullet$ Identifying problems \\
- Reasoning & $\bullet$ Generating evidence \\
- Description & - Evaluating evidence \\
- Explanation & - Drawing conclusions \\
- Prediction & \\
\hline
\end{tabular}

The conceptualizations of professional vision and diagnostic activities are itemized based on Blömeke et al.'s (2015) situation-specific skills 
components without making further judgements" (Seidel \& Stürmer, 2014, p. 745). Explanation includes teachers' use of knowledge to reason about the noticed aspects by linking them to concepts and theories; and prediction is described as teachers deriving consequences from "observed events in terms of student learning" (Seidel \& Stürmer, 2014, p. 746). Additionally, rectifications can be made. These situationspecific skills are considered crucial for professionally observing and interpreting classroom situations and thus also for teachers' performance in the classroom (Borko, 2004; Blömeke et al., 2015).

Epistemic activities can be considered another conceptualization of reasoning skills, which describe activities during reasoning and argumentation (Heitzmann, 2013; Fischer et al., 2014). In the context of diagnostic processes, these activities are called diagnostic activities and are required for generating knowledge (Heitzmann et al., 2019; Chernikova et al., 2022). When diagnosing classroom situations, teachers do not necessarily execute all diagnostic activities. We assume that identifying problems, generating evidence, evaluating evidence, and drawing conclusions are of particular interest when diagnosing the classroom situations in DiKoBi. Identifying problems occurs when teachers identify a problematic event within a classroom situation. For generating evidence, different approaches exist: Either evidence can be generated in a hypothetico-deductive approach with an experimental design or in an inductive approach. The inductive approach might be particularly relevant with regard to the diagnosis of classroom situations. Here, problematic events are observed, compared, and described in a purposeful way. Evaluating evidence occurs when teachers assess their observed and described evidence regarding its support for a claim or theory. Drawing conclusions occurs when teachers make predictions concerning students' learning or suggest an alternative teaching action. When assigning these activities to the conceptualization of professional vision, identifying problems corresponds to noticing, generating evidence corresponds to description, and drawing conclusions corresponds to prediction. From a theoretical perspective, evidence evaluation might be assigned to explanation. However, the two do not describe exactly the same construct and thus do not overlap completely. Explanation is considered to link a theory to generated evidence, which might be one facet of evidence evaluation (Kramer et al., 2021).

Even though both conceptualizations, professional vision and diagnostic activities, contain situation-specific skills in the context of reasoning, it is not clear as to what degree the two conceptualizations agree with one another and whether combining them to describe diagnostic processes has added value.

\subsubsection{Instructional Quality in Biology Lessons}

Depending on teachers' professional knowledge and situation-specific skills, teachers make pedagogical decisions that at least partially become visible as teaching performance in the classroom (Blömeke et al., 2015). This performance is crucial for teaching effectiveness and thus for instructional quality (Kyriakides et al., 2013). 
Research has identified general features as well as subject-specific features of instructional quality (Wüsten, 2010). General features are classroom management, supportive climate, and cognitive activation (Baumert et al., 2010; Lipowsky et al., 2009). Classroom management and supportive climate are assumed to act as prerequisites for the implementation of subject-specific features (Dorfner et al., 2018b). Cognitive activation requires the specific subject to be taken into account (Förtsch et al., 2017). To achieve this subject specificity, Wüsten (2010) compiled a classification of biology-specific features that are important for instructional quality in biology lessons. These include content structuring of the lesson, complexity of tasks, cumulative learning, use of technical language, dealing with students' errors and feedback, use of models, use of experiments, and scientific working methods. Research has shown that the clarity of goals had positive effects on students' learning and motivation (Seidel et al., 2005b). Also, an error-tolerant classroom culture showed positive effects on the affective level (Rach et al., 2013). Furthermore, knowledge linking as part of cumulative learning turned out to foster students' knowledge structure (Wadouh et al., 2014). By teaching interrelated facts and concepts instead of isolated facts, students were cognitively activated. Cognitive activation is considered to be a key feature of instructional quality in biology lessons and is associated with several of the above-mentioned features of instructional quality (Dorfner et al., 2018b; Förtsch et al., 2017). Cognitive activation can be influenced via tasks that promote students' cognitive engagement (Chi \& Wylie, 2014). Additionally, students' learning can be fostered by a sophisticated use of models that increases scientific reasoning skills (Förtsch et al., 2018b). Scientific reasoning is also important when solving problems in biology (Dorfner et al., 2018a; Mayer, 2007). When using experiments, embedding them in everyday life contexts is a predictor for instructional quality (Tesch \& Duit, 2004). The implementation of process variables during experiments can be seen as part of this embedding, which fosters scientific reasoning (Mayer, 2007). Teachers might also have to reconsider their use of professional terms in biology lessons. Dorfner et al. (2019) emphasized that using a high number of professional terms negatively affects students' learning and interest.

To summarize, much effort has been made in research on instructional quality features to identify subject-specific features and foster teachers' knowledge about these features that greatly influence students' learning (Seidel \& Shavelson, 2007). Therefore, fostering teachers' subject-specific knowledge is vitally important in terms of effective teaching and its evaluation.

\subsubsection{Scaffolds for Facilitating Diagnostic Competences}

When seeking to establish instructional quality, diagnostic competences (professional knowledge, situation-specific skills, and performance) are a crucial part of teachers' expertise (Blömeke et al., 2015). Hence, situations that foster the acquisition of diagnostic competences, and thus the transfer of professional knowledge to 
practice, are needed (Heitzmann, 2013). These situations can be provided by videobased instruments such as simulations (Seidel \& Stürmer, 2014). To support teachers in applying their knowledge when diagnosing classroom situations, scaffolds can be used. Scaffolds can be seen as an adaptive support for teachers in carrying out tasks or trying to achieve certain goals (Quintana et al., 2004).

One approach to fostering the acquisition and application of professional knowledge is the use of prompts during the solution of the task as a scaffolding option. Prompts can be content-related and thus support novice teachers in activating relevant knowledge structures and linking them to the teaching situation by referring to specific information; or they can provide strategic hints on how to effectively execute diagnostic activities (cf. Wildgans-Lang et al., 2022; Hannafin et al., 1999; Seidel \& Stürmer, 2014). Thus, teachers can develop new connections between their knowledge structures and their classroom performance. Research on the teaching of foreign languages has shown that video-based simulations can foster teachers' application of PK and PCK to their own classroom teaching under certain conditions. The effect occurred only if pre-service teachers were supported by hints from the video-based simulations shown to them before they interacted with a simulation (Goeze et al., 2014). Since the effects of different types of prompts and their embedding in simulations have not yet been investigated, further systematic studies are necessary.

\subsection{Research Questions and Objectives}

As there is hardly any research measuring teachers' diagnostic competences in light of contextualized and situated real-world biology demands (Blömeke et al., 2015), this project investigated pre-service teachers diagnosing real classroom situations in the context of a video-based simulation named DiKoBi. The situations are focused on the whole class to give participants the opportunity to apply their diagnostic competences with a subject-specific view under conditions similar to real classrooms. More precisely, we want to investigate the relation between professional knowledge; the use of situation-specific skills, which are operationalized as diagnostic activities and professional vision; and the quality of the diagnostic results. Within this project, we focus on the facilitation of professional knowledge as part of diagnostic competences, and its influence on the execution of situation-specific skills and the accuracy and efficiency of the diagnostic results. Additionally, the effects of addressing the different knowledge facets in a successive or integrated way during teachers' acquisition of professional knowledge are investigated. We use our developed video-based simulation DiKoBi to measure situation-specific skills, the accuracy and efficiency of the diagnostic results. Furthermore, we want to investigate how diagnostic competences can be fostered with DiKoBi. Therefore, we analyze the influence of scaffolding by using different prompts during the solution of the task. The main research questions of the project are: 
1. What is the relation between the different facets of professional knowledge $(\mathrm{CK}$, PCK, and PK) and the use of situation-specific skills as well as the quality of the diagnostic results?

2. What are the effects of addressing CK, PCK, and PK in (a) a successive way or (b) in an integrated way on the acquisition of diagnostic competences?

3. What are the effects of prompting (regarding content or diagnostic activities) during the solution of the tasks in DiKoBi on the acquisition of diagnostic competences among pre-service teachers with different levels of professional knowledge?

\subsection{Video-Based Simulation}

In this project, the German online learning platform DiKoBi serves as a video-based simulation, in which six classroom situations are embedded. The classroom situations represent challenging dimensions in biology classrooms: (1) students' level of cognitive activities (Förtsch et al., 2016), (2) dealing with students' ideas and errors (Rach et al., 2013), (3) use of technical language (Dorfner et al., 2019; Wüsten, 2010), (4) use of experiments (Mayer, 2007), (5) use of models (Förtsch et al., 2018b; Werner et al., 2017), and (6) conceptual understanding (Förtsch et al., 2017). Pre-service teachers had to diagnose effective teaching using DiKoBi. To represent a real-world context, the classroom situation for diagnosis focuses on interactions between a teacher and a whole class, not a single student. Thus, the diagnostic situation is individual and based on (observed) interaction (Chernikova et al., 2022).

To show specific classroom situations, staged videos were recorded and embedded in the learning platform. The use of staged videos is considered an appropriate method for analyzing the complex situations of classroom teaching and learning as well as measuring teachers' expertise in such classroom situations, where teacher knowledge is activated by the real-life context (Hoth et al., 2018; Kersting et al., 2010; Stürmer \& Seidel, 2015).

\subsubsection{Development of Staged Videos}

We scripted three consecutive lessons on the topic of 'skin' to be videotaped, focusing on three different subtopics. By doing this, we were able to vary the lesson shown in the videos in case participants use DiKoBi more than once. Instruction on the subtopics was guided by standards from the Bavarian curriculum on the content area 'senses and sensory organs' (State Institute of School Quality and Educational Research Munich, 2018). The first lesson focuses on the subtopic "skin as a sensory organ" in Grade 5, the second lesson on the subtopic "protective functions of the skin," and the third lesson on the subtopic "regulation of body temperature." Each 
lesson was divided into six cases, each focusing on a different instructional quality feature of biology lessons.

For each of the six dimensions of instructional quality, we videotaped lessons on three different quality levels based on scripts. For each case, there is a basic version showing a part of the lesson in which relevant features of the dimension of instructional quality under study are missing. Additionally, there are two other versions showing alternative teaching strategies considering the relevant instructional quality features. To ensure the comparability of the three video versions, the content of the lessons shown in the video for each instructional quality feature is identical. We ultimately prepared 18 simulated video cases for each of the three lessons.

The staged video cases were videotaped in school afternoon workshops at a secondary school in Bavaria (for a more detailed description, see Kramer et al., 2020). The workshop took place in a science classroom, which was equipped with cameras for videotaping lessons. The teacher and all speaking students used microphones to improve the sound quality. The workshop program included time for textbook learning, practicing, and video recording.

\subsubsection{Use of Simulation and Diagnostic Process}

The diagnostic process was measured with three different tasks that require situationspecific skills for diagnosing. First, participants have to watch the video and identify challenging aspects of the classroom situation by noting them down in open text fields in the simulation on the computer (for Task Describe, see Fig. 6.1). Second, participants are asked to reason about their described aspects by linking them to subject-related pedagogical theories and concepts (Task Explain). Additionally, they have to estimate their confidence about their reflections on the classroom situation by adjusting a slider on a questionnaire scale (from completely unconfident to very confident). Third, participants have to propose an alternative teaching strategy and explain why their selected strategy would improve the classroom situation (Task Alternative Strategy). Again, for each classroom situation, participants have to estimate how confident they feel about their described and explained alternative teaching strategy (see Fig. 6.2).

Last, the learning environment DiKoBi can be extended depending on the aim of measurement. In the extended version, participants watch two videos showing teaching alternatives at the end of each of the six different classroom situations, and they are asked to decide which alternative is better from their perspective. In addition, they have to explain using their professional knowledge why they chose the selected alternative. However, a reduced version without video alternatives can be used to measure diagnostic competences. The extended version showing the teaching alternatives can be used to propose ways to optimize the presented classroom situation.

Diagnostic accuracy is determined based on the participants' answers from the text fields, which are assessed with a coding scheme. The coding scheme is theory- 
Task Describe

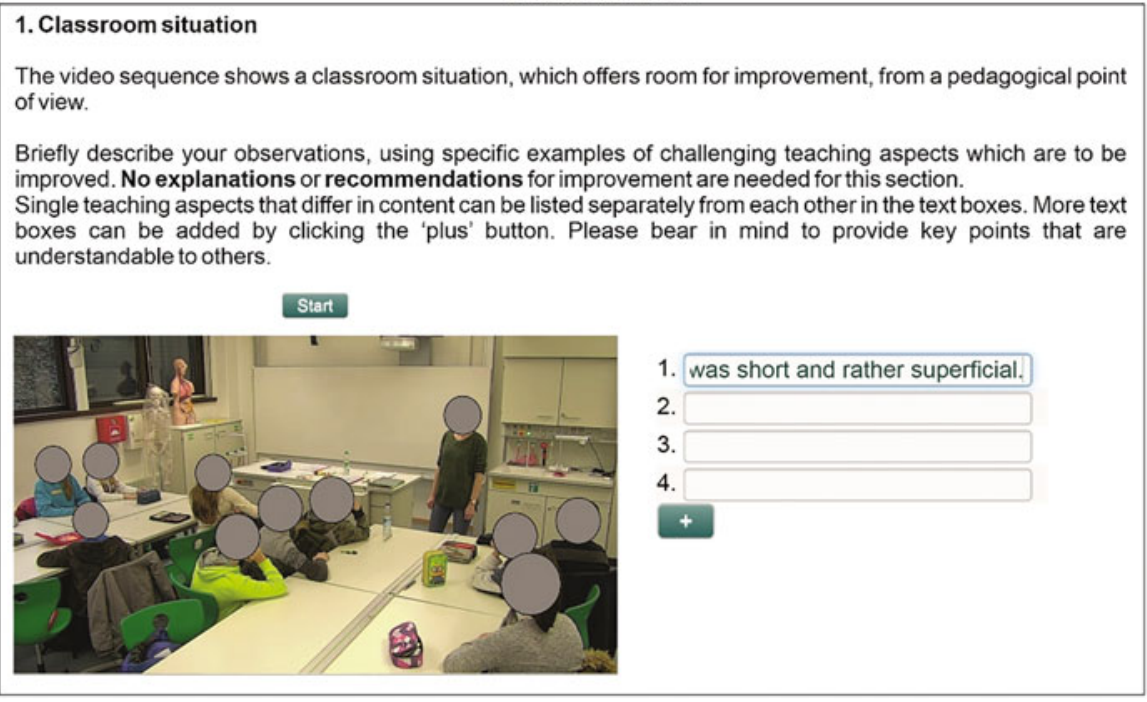

Fig. 6.1 Design of the first task. Participants are asked to note identified challenging teaching aspects in the open text fields on the right

based and includes references to biology-specific features of instructional quality, to which participants have to refer during the diagnostic processes. Diagnostic efficiency can be determined based on the participants' time spent completing the tasks in relation to accuracy. The coding scheme also includes descriptions for coding the participants' diagnostic competences based on their conceptualizations of professional vision and diagnostic activities.

\subsubsection{Generating Data with DiKoBi}

In the following example, the process of data generation to measure situationspecific skills in the context of diagnosing instructional quality is elaborated for a teacher named Paul, illustratively shown for the Task Describe and the Task Alternative Strategy with reference to diagnosing the first classroom situation in $\mathrm{DiKoBi}$. The assigned tasks guide the diagnostic process and therefore the execution of situation-specific skills.

Table 6.2 presents Paul's answers as well as the corresponding codings and their operationalization within the different conceptualizations. After watching the video of the first classroom situation, the Task Describe asks for a description of challenging aspects of the watched classroom situation. To answer the Task Describe, Paul has to generate information by describing the problem he has identified in the classroom situation. Paul's note (The introduction was short and rather superficial) 


\section{Task Explain}

\section{Classroom situation}

Explain, with reasoning, as to how you see room for improvement of the classroom situation.

Use pedagogical theories for an evidence-based rationale. In the text box on the left you can find a teaching aspect you mentioned before. Note the associated pedagogical theory or theories in the text box on the right.

Please bear in mind to provide key points that are understandable to others.

Attention: Do not describe concrete recommendations here.

the introduction was short and rather superficial

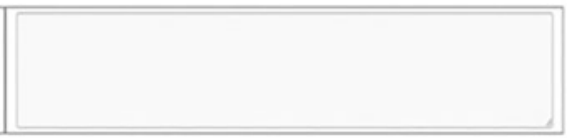

How confident do you feel about your reflections on this classroom situation?

Completely unconfident

Very confident

Task Alternative Strategy

\section{Classroom situation}

Now describe how to perform teaching more skillfully as a teacher, from a pedagogical viewpoint. Clarify why you think that your alternative teaching strategy would improve the problematic classroom situation which you have observed in the video.

\section{How confident do you feel about your reflections on this classroom situation?}

Completely unconfident

Very confident

Fig. 6.2 Design of Task Explain and Task Alternative Strategy. Participants are asked for pedagogical rationales as well as alternative teaching strategies. Additionally, participants have to estimate their confidence about the answers they have given 
Table 6.2 Part of the coding scheme used for generating data with DiKoBi

\begin{tabular}{|c|c|c|}
\hline \multirow[b]{2}{*}{ Teacher Paul's answers } & \multicolumn{2}{|c|}{ Situation-specific skills for diagnosing } \\
\hline & $\begin{array}{l}\text { Diagnostic activities } \\
\text { (Fischer et al., 2014; } \\
\text { Heitzmann et al., 2019) }\end{array}$ & $\begin{array}{l}\text { Professional vision } \\
\text { (Seidel \& Stürmer, 2014; van } \\
\text { Es \& Sherin, 2002) }\end{array}$ \\
\hline $\begin{array}{l}\text { Task Describe: Briefly describe } \\
\text { your observations... } \\
\text { The introduction was short and } \\
\text { rather superficial }\end{array}$ & $\begin{array}{l}\text { Generating evidence } \\
\text { Means: Challenging events } \\
\text { are observed, compared } \\
\text { and described purposively }\end{array}$ & $\begin{array}{l}\text { Description } \\
\text { Means: Relevant events that } \\
\text { influence instructional quality } \\
\text { and thus students' learning are } \\
\text { listed }\end{array}$ \\
\hline $\begin{array}{l}\text { Task Alternative strategy: } \\
\text { Describe how to perform teach- } \\
\text { ing more skillfully... } \\
\text { The teacher could compare the } \\
\text { skin and its tasks with a jacket } \\
\text { and its tasks. By doing so, he } \\
\text { can extrapolate functions of the } \\
\text { skin from its structures and fea- } \\
\text { tures to conclude that functional } \\
\text { aspects depend on structural } \\
\text { features }\end{array}$ & $\begin{array}{l}\text { Drawing conclusions } \\
\text { Means: Consequences that } \\
\text { lead to redesign of behavior } \\
\text { or environment are derived }\end{array}$ & $\begin{array}{l}\text { Prediction } \\
\text { Means: Consequences of } \\
\text { observed events or alternative } \\
\text { teaching strategies are derived }\end{array}$ \\
\hline
\end{tabular}

For illustrative purposes, answers from a teacher named Paul are presented and matched with codings from the different conceptualizations

refers to the biology-specific feature "level of students' cognitive activities", which can be enhanced, for example, by reactivating students' prior knowledge. Paul's note shows that he described the observation he made without any further judgments. Thus, he generated evidence for further reasoning. Accordingly, we can code generating evidence as the situation-specific skill that occurs using the conceptualization of diagnostic activities. The Task Alternative Strategy asks for a description of an alternative teaching strategy to improve on the identified problem. The task targets teachers' ability to conclude how teaching could be performed more skillfully. Paul's answer shows that his alternative strategy supports cognitive activation by comparing structures and functions. Thus, we can code drawing conclusions as the situation-specific skill that occurs.

To sum up, by matching teachers' answers with diagnostic activities or aspects of professional vision, we measure situation-specific skills in the process of diagnosing as indicators of diagnostic competences.

\subsection{Validation of DiKoBi as a Measurement Instrument}

To investigate the validity of DiKoBi for measuring situation-specific skills as part of diagnostic competences, the content and tasks were validated with (a) interviews using think-aloud protocols (Kramer et al., 2020) and (b) expert-novice 
comparisons. Moreover, the comparability of diagnostic activities and aspects of professional vision as situation-specific skills were examined. Thus, we seek to contribute to clarifying and expanding conceptualizations used in interdisciplinary research fields. (a) Interviews using think-aloud protocols were conducted with five experts who were biology teachers at German secondary schools with an average teaching experience of 9.4 years after teacher training ( $S D=6.9$ years). These experts first watched the six classroom situations to identify challenging teaching aspects. Second, they worked on one classroom situation from DiKoBi by answering the items in the simulation while thinking aloud. Afterwards, their protocols were transcribed and analyzed using qualitative content analysis (Mayring, 2014). Each statement made by the experts in the interviews was matched with one category from professional vision and one from diagnostic activities. The results showed that almost all of our scripted problems were identified in the interviewees' statements, and that the created tasks measure situation-specific skills of the diagnostic process. The results of the comparison of professional vision and diagnostic activities showed that generating evidence as a diagnostic activity matched the professional vision aspect description, and drawing conclusions matched the professional vision aspect prediction. The diagnostic activity evidence evaluation included explanatory statements, which linked theories and evidence. Additionally, there were evaluative statements that contained a personal assessment of the quality of the generated evidence. The assessment referred to the degree to which the evidence supported the identified challenging classroom situation. The comparison with professional vision showed that explanatory parts of evidence evaluation matched the professional vision aspect explanation (Kramer et al., 2021). (b) For the expert-novice comparison, 15 in-service teachers with an average teaching experience of 6.1 years $(S D=5.9)$ and 64 pre-service teachers with an average length of study of 2.2 semesters $(S D=0.7)$ worked on DiKoBi. Both experts and novices examined the authenticity of the diagnostic situations presented in the videos. Furthermore, experts' and novices' answers in the open text fields were analyzed for each of the six simulated classroom situations. The described challenges, theoretical rationales, and selected alternatives by experts and novices were compared in terms of the situation-specific skills used. Initial results showed that both experts and novices assessed the videos as authentic. Furthermore, experts used situation-specific skills more extensively.

The above validation results points out that DiKoBi can be used as a valid instrument for measuring diagnostic competences concerning instructional quality. Additionally, we showed that the concepts of professional vision and diagnostic activities contain facets that can be used for conceptual refinement, as we did for the diagnostic activity evaluating evidence. Thus, the results promote the understanding of the research projects' fundamental principles based on common disciplinespecific theories. 


\subsection{Interdisciplinary Collaboration}

The interdisciplinary collaboration within this project combines expertise on research on teachers' professional competences (e.g., Jüttner \& Neuhaus, 2013), video-based teaching (e.g., Seidel et al., 2005a; Seidel \& Stürmer, 2014; Ufer \& Reiss, 2010), as well as on learning and computer-supported case-based learning in both the mathematical (e.g., Lindmeier, 2011) and medical contexts (e.g., Kopp et al., 2009; Stark et al., 2011). The experiences from this interdisciplinary collaboration enabled us to build the computer-supported video-based simulation DiKoBi, in which different features of instructional quality in biology lessons are presented in the form of staged videos. In accordance with Seidel and Stürmer (2014), who developed a video-based instrument called the Observer Research Tool for measuring professional vision in classroom situations, we developed the biology-specific instrument $\mathrm{DiKoBi}$, which can be used to examine the development of professional vision among pre-service biology teachers. The Observer Research Tool project also investigated which competences teachers need to develop to cope with classroom situations successfully (Koster et al., 2005). The experiences and concepts from the interdisciplinary collaboration can be used to analyze diagnostic competences in a wider approach.

\subsection{Conclusion and Possible Applications}

This chapter describes the conceptualization, design, and development of the videobased simulation DiKoBi, which focuses on diagnosing effective teaching in terms of instructional quality in the context of biology lessons. A validation study showed that DiKoBi can be used to measure situation-specific skills that are used during diagnostic processes (Kramer et al., 2020). DiKoBi could potentially be used in university courses as a learning environment for professional vision. Additionally, the staged videos from the simulations can be used separately for analyzing teaching examples, discussing features of instructional quality, and linking them to professional terms and concepts. Going forward, we want to contribute to Questions 2 and 4 of the overarching research questions mentioned in the introduction by Fischer et al. (2022) and in the concluding chapter by Opitz et al. (2022). We plan to address the question of how best to support pre-service teachers' learning outcomes by investigating effects of scaffolds such as content-related prompts or prompts focused on diagnostic activities. Furthermore, depending on pre-service teachers' professional knowledge, we want to adapt the scaffolds used in the simulation to better fit learners. Altogether, the developed instrument and its components represent a videobased simulation with the potential to support teachers in transferring professional knowledge to actual decisions in classroom teaching. 
Acknowledgments The research presented in this chapter was funded by a grant from the Deutsche Forschungsgemeinschaft (DFG-FOR 2385) to Birgit Neuhaus, Tina Seidel, Stefan Ufer, and Martin R. Fischer (NE 1196/8-1).

\section{References}

Baumert, J., \& Kunter, M. (2013). The COACTIV model of teachers' professional competence. In M. Kunter, J. Baumert, W. Blum, U. Klusmann, S. Krauss, \& M. Neubrand (Eds.), Cognitive activation in the mathematics classroom and professional competence of teachers. Results from the coactiv project (pp. 25-48). Springer.

Baumert, J., Kunter, M., Blum, W., Brunner, M., Voss, T., Jordan, A., et al. (2010). Teachers' mathematical knowledge, cognitive activation in the classroom, and student Progress. American Educational Research Journal, 47, 133-180. https://doi.org/10.3102/0002831209345157

Blömeke, S., \& Kaiser, G. (2017). Understanding the development of teachers' professional competencies as personally, situationally and socially determined. In D. J. Clandinin \& J. Husu (Eds.), International handbook of research on teacher education (pp. 783-802). Sage.

Blömeke, S., Kaiser, G., \& Lehmann, R. (Eds.). (2010). TEDS-M 2008: Professionelle Kompetenz und Lerngelegenheiten angehender Mathematiklehrkräfte für die Sekundarstufe I im internationalen Vergleich. Waxmann.

Blömeke, S., Gustafsson, J.-E., \& Shavelson, R. J. (2015). Beyond dichotomies. Zeitschrift für Psychologie, 223, 3-13. https://doi.org/10.1027/2151-2604/a000194

Borko, H. (2004). Professional development and teacher learning: Mapping the terrain. Educational Researcher, 33(8), 3-15.

Borko, H., Roberts, S. A., \& Shavelson, R. (2008). Teachers' decision making: From Alan J. bishop to today. In P. Clarkson \& N. Presmeg (Eds.), Critical issues in mathematics education: Major contributions of Alan bishop (1st ed., pp. 37-67). Springer US.

Bricker, L. A., \& Bell, P. (2008). Conceptualizations of argumentation from science studies and the learning sciences and their implications for the practices of science education. Science Education, 92, 473-498. https://doi.org/10.1002/sce.20278

Chernikova, O., Heitzmann, N., Opitz, A., Seidel, T., \& Fischer, F. (2022). A theoretical framework for fostering diagnostic competences with simulations. In F. Fischer \& A. Opitz (Eds.), Learning to diagnose with simulations-Examples from teacher education and medical education. Springer briefs in education series. Springer.

Chi, M. T. H., \& Wylie, R. (2014). The ICAP framework: Linking cognitive engagement to active learning outcomes. Educational Psychologist, 49, 219-243. https://doi.org/10.1080/00461520. 2014.965823

Darling-Hammond, L. (2010). Teacher education and the American future. Journal of Teacher Education, 61, 35-47. https://doi.org/10.1177/0022487109348024

de Jong, T., \& Ferguson-Hessler, M. G. M. (1996). Types and qualities of knowledge. Educational Psychologist, 31(2), 105-113.

Dorfner, T., Förtsch, C., Germ, M., \& Neuhaus, B. J. (2018a). Biology instruction using a generic framework of scientific reasoning and argumentation. Teaching and Teacher Education, 75, 232-243. https://doi.org/10.1016/j.tate.2018.07.003

Dorfner, T., Förtsch, C., \& Neuhaus, B. J. (2018b). Effects of three basic dimensions of instructional quality on students' situational interest in sixth-grade biology instruction. Learning and Instruction, 56, 42-53. https://doi.org/10.1016/j.learninstruc.2018.03.001 
Dorfner, T., Förtsch, C., \& Neuhaus, B. J. (2019). Use of technical terms in German biology lessons and its effects on students' conceptual learning. Research in Science and Technological Education, 38, 227-251. https://doi.org/10.1080/02635143.2019.1609436

Fischer, F., Kollar, I., Ufer, S., Sodian, B., Hussmann, H., Pekrun, R., et al. (2014). Scientific reasoning and argumentation: Advancing an interdisciplinary research agenda in education. Frontline Learning Research, 5, 28-45.

Förtsch, C., Werner, S., von Kotzebue, L., \& Neuhaus, B. J. (2016). Effects of biology teachers' professional knowledge and cognitive activation on students' achievement. International Journal of Science Education, 38, 2642-2666. https://doi.org/10.1080/09500693.2016.1257170

Förtsch, C., Werner, S., Dorfner, T., von Kotzebue, L., \& Neuhaus, B. J. (2017). Effects of cognitive activation in biology lessons on students' situational interest and achievement. Research in Science Education, 47, 559-578. https://doi.org/10.1007/s11165-016-9517-y

Förtsch, C., Sommerhoff, D., Fischer, F., Fischer, M., Girwidz, R., Obersteiner, A., et al. (2018a). Systematizing professional knowledge of medical doctors and teachers: Development of an interdisciplinary framework in the context of diagnostic competences. Educational Sciences, 8, 207. https://doi.org/10.3390/educsci8040207

Förtsch, S., Förtsch, C., von Kotzebue, L., \& Neuhaus, B. (2018b). Effects of teachers' professional knowledge and their use of three-dimensional physical models in biology lessons on students' achievement. Educational Sciences, 8, 118. https://doi.org/10.3390/educsci8030118

Goeze, A., Zottmann, J. M., Vogel, F., Fischer, F., \& Schrader, J. (2014). Getting immersed in teacher and student perspectives?: Facilitating analytical competence using video cases in teacher education. Instructional Science, 42, 91-114. https://doi.org/10.1007/s11251-0139304-3

Goodwin, C. (1994). Professional vision. American Anthropologist, 96(3), 606-633.

Grossman, P., \& McDonald, M. (2008). Back to the future: Directions for research in teaching and teacher education. American Educational Research Journal, 45, 184-205. https://doi.org/10. 3102/0002831207312906

Hannafin, M. J., Land, S. M., \& Oliver, K. M. (1999). Open learning environments: Foundations, methods, and models. In C. M. Reigeluth (Ed.), Instructional-design-theories and models: A new paradigm of instructional theory (pp. 115-140). Lawrence Erlbaum.

Heitzmann, N. (2013). Fostering diagnostic competence in different domains. Dissertation. Ludwig-Maximilians-Universität.

Heitzmann, N., Seidel, T., Opitz, A., Hetmanek, A., Wecker, C., Fischer, M., Ufer, S., Schmidmaier, R., Neuhaus, B., Siebeck, M., Stürmer, K., Obersteiner, A., Reiss, K., Girwidz, R., \& Fischer, F. (2019). Facilitating diagnostic competences in simulations in higher education. Frontline Learning Research, 7(4), 1-24. https://doi.org/10.14786/flr.v7i4.384

Helmke, A., \& Lenske, G. (2013). Unterrichtsdiagnostik als Voraussetzung für Unterrichtsentwicklung. Beiträge zur Lehrerbildung, 31(2), 214-233.

Hill, H. C., Ball, D. L., Blunk, M., Goffney, I. M., \& Rowan, B. (2007). Validating the ecological assumption: The relationship of measure scores to classroom teaching and student learning. Measurement: Interdisciplinary Research \& Perspective, 5, 107-118. https://doi.org/10.1080/ 15366360701487138

Hoth, J., Kaiser, G., Döhrmann, M., König, J., \& Blömeke, S. (2018). A situated approach to assess teachers' professional competencies using classroom videos. In O. Buchbinder \& S. Kuntze (Eds.), Mathematics teachers engaging with representations of practice: A dynamically evolving field. ICME-13 Monographs (pp. 23-45). Springer.

Hume, A., Cooper, R., \& Borowski, A. (Eds.). (2019). Repositioning pedagogical content knowledge in teachers' knowledge for teaching science. Springer. 
Jüttner, M., \& Neuhaus, B. J. (2013). Validation of a paper-and-pencil test instrument measuring biology teachers' pedagogical content knowledge by using think-aloud interviews. Journal of Education and Training Studies, 1(2), 113-125. https://doi.org/10.11114/jets.v1i2.126

Kersting, N. B., Givvin, K. B., Sotelo, F. L., \& Stigler, J. W. (2010). Teachers' analyses of classroom video predict student learning of mathematics: Further explorations of a novel measure of teacher knowledge. Journal of Teacher Education, 61, 172-181. https://doi.org/ $10.1177 / 0022487109347875$

Kersting, N. B., Givvin, K. B., Thompson, B. J., Santagata, R., \& Stigler, J. W. (2012). Measuring usable knowledge: Teachers' analyses of mathematics classroom videos predict teaching quality and student learning. American Educational Research Journal, 49(3), 568-589.

Kleickmann, T., Tröbst, S., Heinze, A., Bernholt, A., Rink, R., \& Kunter, M. (2017). Teacher knowledge experiment: Conditions of the development of pedagogical content knowledge. In D. Leutner, J. Fleischer, J. Grünkorn, \& E. Klieme (Eds.), Competence assessment in education: Research, models and instruments. Methodology of educational measurement and assessment (Vol. 59, pp. 111-129). Springer International.

Kolodner, J. L. (1992). An introduction to case-based reasoning. Artificial Intelligence Review, 6, 3-34. https://doi.org/10.1007/BF00155578

Kopp, V., Stark, R., \& Fischer, M. R. (2009). Förderung von Diagnosekompetenz durch fallbasiertes Lernen mit ausgearbeiteten Lösungsbeispielen: Evaluation einer computerbasierten Lernumgebung. Unterrichtswissenschaft, 37, 17-34. https://doi.org/10.3262/UW0901017

Koster, B., Brekelmans, M., Korthagen, F., \& Wubbels, T. (2005). Quality requirements for teacher educators. Teaching and Teacher Education, 21, 157-176. https://doi.org/10.1016/j.tate.2004. 12.004

Kramer, M., Förtsch, C., Stürmer, J., Förtsch, S., Seidel, T., \& Neuhaus, B. J. (2020). Measuring biology teachers' professional vision: Development and validation of a video-based assessment tool. Cogent Journal, 7(1), 1-28. https://doi.org/10.1080/2331186X.2020.1823155

Kramer, M., Förtsch, C., Seidel, T., \& Neuhaus, B. J. (2021). Comparing Two Constructs for Describing and Analyzing Teachers' Diagnostic Processes. Studies in Educational Evaluation, 28. https://doi.org/10.1016/j.stueduc.2020.100973

Kyriakides, L., Christoforou, C., \& Charalambous, C. Y. (2013). What matters for student learning outcomes: A meta-analysis of studies exploring factors of effective teaching. Teaching and Teacher Education, 36, 143-152. https://doi.org/10.1016/j.tate.2013.07.010

Lindmeier, A. (2011). Modeling and measuring knowledge and competencies of teachers: A threefold domain-specific structure model for mathematics (Empirische Studien zur Didaktik der Mathematik) (Vol. 7). Waxmann.

Lipowsky, F., Rakoczy, K., Pauli, C., Drollinger-Vetter, B., Klieme, E., \& Reusser, K. (2009). Quality of geometry instruction and its short-term impact on students' understanding of the Pythagorean theorem. Learning and Instruction, 19, 527-537. https://doi.org/10.1016/j. learninstruc.2008.11.001

Mayer, J. (2007). Erkenntnisgewinnung als wissenschaftliches Problemlösen. In D. Krüger \& H. Vogt (Eds.), Theorien in der biologiedidaktischen Forschung: Ein Handbuch für Lehramtsstudenten und Doktoranden (pp. 177-186). Springer.

Mayring, P. (2014). Qualitative content analysis: Theoretical foundation, basic procedures and software solution. Beltz. Retrieved December 18, 2018, from https://www.psychopen.eu/ fileadmin/user_upload/books/mayring/ssoar-2014-mayring-Qualitative_content_analysis_theo retical_foundation.pdf.

O’Donnell, A., \& Levin, J. R. (2001). Educational Psychology's healthy growing pains. Educational Psychologist, 36(2), 73-82. 
Prawat, R. S. (1989). Promoting access to knowledge, strategy, and disposition in students: A research synthesis. Review of Educational Research, 59, 1-41. https://doi.org/10.2307/1170445

Quintana, C., Reiser, B. J., Davis, E. A., Krajcik, J., Fretz, E., Duncan, R. G., et al. (2004). A scaffolding design framework for software to support science inquiry. Journal of the Learning Sciences, 13, 337-386. https://doi.org/10.1207/s15327809j1s1303_4

Rach, S., Ufer, S., \& Heinze, A. (2013). Learning from errors: Effects of teachers' training on students' attitudes towards and their individual use of errors. Proceedings of the National Academy of Sciences, 8(1), 21-30.

Santagata, R., \& Yeh, C. (2016). The role of perception, interpretation, and decision making in the development of beginning teachers' competence. ZDM, 48, 153-165. https://doi.org/10.1007/ s11858-015-0737-9

Seidel, T., \& Shavelson, R. J. (2007). Teaching effectiveness research in the past decade: The role of theory and research design in disentangling meta-analysis results. Review of Educational Research, 77, 454-499. https://doi.org/10.3102/0034654307310317

Seidel, T., \& Stürmer, K. (2014). Modeling and measuring the structure of professional vision in preservice teachers. American Educational Research Journal, 51, 739-771. https://doi.org/10. 3102/0002831214531321

Seidel, T., Prenzel, M., \& Kobarg, M. (2005a). How to run a video study: Technical report of the IPN video study. Waxmann.

Seidel, T., Rimmele, R., \& Prenzel, M. (2005b). Clarity and coherence of lesson goals as a scaffold for student learning. Learning and Instruction, 15, 539-556. https://doi.org/10.1016/j. learninstruc.2005.08.004

Shavelson, R. J., Young, D. B., Ayala, C. C., Brandon, P. R., Furtak, E. M., Ruiz-Primo, M. A., et al. (2008). On the impact of curriculum-embedded formative assessment on learning: A collaboration between curriculum and assessment developers. Applied Measurement in Education, 21, 295-314. https://doi.org/10.1080/08957340802347647

Shulman, L. S. (1987). Knowledge and teaching: Foundations of the new reform. Havard Educational Review, 57, 1-22.

Stahnke, R., Schueler, S., \& Roesken-Winter, B. (2016). Teachers' perception, interpretation, and decision-making: A systematic review of empirical mathematics education research. ZDM, 48, 1-27. https://doi.org/10.1007/s11858-016-0775-y

Stark, R., Kopp, V., \& Fischer, M. R. (2011). Case-based learning with worked examples in complex domains: Two experimental studies in undergraduate medical education. Learning and Instruction, 21, 22-33. https://doi.org/10.1016/j.learninstruc.2009.10.001

State Institute of School Quality and Educational Research Munich. (2018). Lehrplan PLUS. Retrieved December 12, 2018, from https://www.lehrplanplus.bayern.de/fachlehrplan/gymna sium $/ 5 /$ nt_gym.

Stürmer, K., \& Seidel, T. (2015). Assessing professional vision in teacher candidates. Zeitschrift für Psychologie, 223, 54-63. https://doi.org/10.1027/2151-2604/a000200

Südkamp, A., \& Praetorius, A.-K. (Eds.). (2017). Diagnostische Kompetenz von Lehrkräften. Waxmann.

Tesch, M., \& Duit, R. (2004). Experimentieren im Physikunterricht - Ergebnisse einer Videostudie. Zeitschrift für Didaktik der Naturwissenschaften, 10, 51-69.

Ufer, S., \& Reiss, K. (2010). Inhaltsübergreifende und inhaltsbezogene strukturierende Merkmale von Unterricht zum Beweisen in der Geometrie - eine explorative Videostudie. Unterrichtswissenschaft, 38, 247-265. 
van Es, E., \& Sherin, M. (2002). Learning to notice: Scaffolding new teachers' interpretations of classroom interactions. Journal of Technology and Teacher, 10(4), 571-596.

Wadouh, J., Liu, N., Sandmann, A., \& Neuhaus, B. J. (2014). The effect of knowledge linking levels in biology lessons upon students' knowledge structure. International Journal of Science and Mathematics Education, 12, 25-47.

Werner, S., Förtsch, C., Boone, W., von Kotzebue, L., \& Neuhaus, B. J. (2017). Investigating how german biology teachers use three-dimensional physical models in classroom instruction: A video study. Research in Science Education, 1, 195. https://doi.org/10.1007/s11165-0179624-4

Wildgans-Lang, A., Scheuerer, S., Obersteiner, A., Fischer, F., \& Reiss, C. (2022). Learning to diagnose primary students' mathematical competence levels and misconceptions in documentbased simulations. In F. Fischer \& A. Opitz (Eds.), Learning to diagnose with simulationsexamples from teacher education and medical education. Springer.

Wüsten, S. (2010). Allgemeine und fachspezifische Merkmale der Unterrichtsqualität im Fach Biologie: Eine Video- und Interventionsstudie. Dissertation. Universität Duisburg-Essen.

Open Access This chapter is licensed under the terms of the Creative Commons Attribution 4.0 International License (http://creativecommons.org/licenses/by/4.0/), which permits use, sharing, adaptation, distribution and reproduction in any medium or format, as long as you give appropriate credit to the original author(s) and the source, provide a link to the Creative Commons license and indicate if changes were made.

The images or other third party material in this chapter are included in the chapter's Creative Commons license, unless indicated otherwise in a credit line to the material. If material is not included in the chapter's Creative Commons license and your intended use is not permitted by statutory regulation or exceeds the permitted use, you will need to obtain permission directly from the copyright holder.

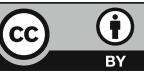

